\title{
A hybrid technique of intracavitary and interstitial brachytherapy for locally advanced cervical cancer: initial outcomes of a single-institute experience
}

\author{
Naoya Murakami ${ }^{1 *}$ D, Kazuma Kobayashi', Satoshi Shima ${ }^{1}$, Keisuke Tsuchida', Tairo Kashihara', Nikolaos Tselis ${ }^{5}$, \\ Rei Umezawa' ${ }^{1}$, Kana Takahashi', Koji Inaba', Yoshinori Ito ${ }^{1}$, Hiroshi Igaki ${ }^{1}$, Yuko Nakayama ${ }^{1}$, Koji Masui ${ }^{3}$, \\ Ken Yoshida ${ }^{4}$, Tomoyasu Kato ${ }^{2}$ and Jun Itami ${ }^{1}$
}

\begin{abstract}
Background: Locally advanced uterine cervical cancer (LAUCC) with lateral tumor extension may not always be covered adequately by conventional intracavitary brachytherapy (ICBT). Hybrid intracavitary and interstitial brachytherapy (HBT) seems to be an effective alternative by improving anatomy-oriented dose optimisation. The purpose of this study was to report initial clinical result for LAUCC treated by HBT.

Methods: Between January 2012 and November 2015, 42 patients with LAUCC (T1b2-4a) were treated with primary radiation therapy including HBT. Patients with distant metastasis other than para-aortic lymph node spread were excluded from this study. A retrospective analysis was performed for toxicity evaluation and oncological outcome calculation.
\end{abstract}

Results: Median follow-up was 23.2 months (range 13.2-71.4). Two-year overall survival, progression free survival, and local control rate were $81.6,54.4$, and $80.2 \%$, respectively. Seven patients experienced local recurrence (16.6\%). Of those, five were confined to the uterus and two at the parametria. Late adverse events $\geq$ grade 3 were seen in 3 patients.

Conclusions: HBT can generate favorable local control in tumors which cannot be adequately covered by ICBT.

Keywords: Uterine cervical cancer, Hybrid of intracavitary and interstitial brachytherapy, Patterns of recurrence, Brachytherapy

\section{Background}

In the primary management of locally advanced uterine cervical cancer (LAUCC) the addition of brachytherapy to external beam radiation therapy (EBRT) with concurrent cisplatin has shown to be associated with higher cause specific- as well as overall survival [1]. Traditionally, intracavitary brachytherapy (ICBT) with tandem plus ovoids/ring was used for irradiation delivering the treatment dose to specific reference points regardless of target size or shape [2]. Although disease control for smaller tumors which can be well-covered by non-anatomy-oriented conventional ICBT dosimetry is

\footnotetext{
*Correspondence: namuraka@ncc.go.jp

'Department of Radiation Oncology, National Cancer Center Hospital, 5-1-1

Tsukiji, Chuo-ku, Tokyo 104-0045, Japan

Full list of author information is available at the end of the article
}

encouraging, control rates for large or irregular shaped tumors which are inadequately approached with point A dosimetry are unfavorable [3, 4]. To overcome this challenge, image-guided adaptive brachytherapy (IGABT) $[5,6]$ with incorporation of a hybrid intracavitary and interstitial brachytherapy technique (HBT) [7-10] has been implemented resulting in markedly improved clinical outcomes [11]. So far, there is no published prospective trial investigating the superiority of HBT over conventional ICBT in the management of LAUCC even though its advantages seem plausible considering that it enables for individualised, three-dimensional (3D) anatomyoriented dosimetry. However, a phase I/II prospective clinical study is under way testing the feasibility and efficacy of HBT for LAUCC [12].

(c) The Author(s). 2019 Open Access This article is distributed under the terms of the Creative Commons Attribution 4.0 International License (http://creativecommons.org/licenses/by/4.0/), which permits unrestricted use, distribution, and reproduction in any medium, provided you give appropriate credit to the original author(s) and the source, provide a link to the Creative Commons license, and indicate if changes were made. The Creative Commons Public Domain Dedication waiver (http://creativecommons.org/publicdomain/zero/1.0/) applies to the data made available in this article, unless otherwise stated. 
In our department, HBT has been applied since 2012 and the aim of the current analysis was to report our clinical results after HBT for patients with LAUCC.

\section{Methods}

Uterine cervical cancer patients who underwent primary radiation therapy (RT) for LAUCC incorporating at least one HBT application between January 2012 and November 2015 were included in this single-institutional retrospective study. LAUCC was defined as any tumor with a size or shape which cannot be adequately covered by conventional ICBT isodose distribution. This was determined according to findings derived from weekly performed gynecological examinations and interim magnet resonance imaging (MRI) taken within 1 week before initial brachytherapy. Staging work-up included pelvic examination, cystoscopy, chest/pelvic computed tomography (CT), trans-rectal ultrasound (TRUS), and pelvic MRI. Patients with metastases other than para-aortic lymph nodes were excluded from this analysis. Patient's demographics are summarised in Table 1.

\section{Chemotherapy and external beam radiation therapy}

The principles of primary RT of LAUCC in our department are described in detail elsewhere [13, 14]. At this,

Table 1 Patients' characteristics $(n=42)$

\begin{tabular}{|c|c|c|}
\hline Median age (years) & & 59 (range, 30-85) \\
\hline \multirow[t]{2}{*}{ Histologic subtypes } & Squamous & 40 \\
\hline & Adeno & 2 \\
\hline \multirow[t]{6}{*}{$\mathrm{T}$} & IB2 & 3 \\
\hline & $\| \mathrm{A} 2$ & 2 \\
\hline & $\| \mathrm{B}$ & 5 \\
\hline & $\| I I A$ & 1 \\
\hline & $\| I \mathrm{~B}$ & 28 \\
\hline & IVA & 3 \\
\hline \multirow[t]{2}{*}{ N } & 0 & 22 \\
\hline & 1 & 20 \\
\hline Ma & & 6 \\
\hline Tumor diameter $(\mathrm{cm})$ & & 6 (range, 3.9-10.1) \\
\hline \multirow[t]{2}{*}{ Ulceration } & Yes & 20 \\
\hline & No & 22 \\
\hline \multirow[t]{2}{*}{ Hydronephrosis } & Yes & 10 \\
\hline & No & 32 \\
\hline \multirow[t]{2}{*}{ Pyometra } & Yes & 12 \\
\hline & No & 30 \\
\hline \multirow[t]{2}{*}{ Corpus invasion } & Yes & 26 \\
\hline & No & 16 \\
\hline
\end{tabular}

T: primary tumor stage

$\mathrm{N}$ : regional lymph nodal stage

Ma: paraaortic lymph node metastasis patients with tumor size larger than $4 \mathrm{~cm}$ at initial diagnosis and/or lymph node metastasis are candidates for concurrent chemoradiation therapy (CCRT) with weekly administration of cisplatin $\left(40 \mathrm{mg} / \mathrm{m}^{2}\right)$. Patients older than 76 years or without adequate renal function are treated with RT alone.

Radiation therapy was delivered as conventionally fractionated 3D-conformal EBRT by a 4-field box technique using a linear accelerator (Clinac iX or TrueBeam, Varian Medical System, Palo Alto, CA) with 15 MV photons. Treatment planning was based on CT images of 3 $\mathrm{mm}$ slice interval (Aquilion ${ }^{\mathrm{Tm}}$ LB CT scanner, Toshiba Medical System, Japan). The radiation portals covered the whole uterus, parametria, vagina, and the regional lymphatics (pre-sacral nodes, common-, internal-, and external-iliac nodes). The upper and lower margin was set at L4/5 and the lower border of the obturator foramen, respectively. Initially, 30-40 Gy were delivered to the whole pelvis followed by application of an AP-PA central shield (CS) by means of a $4 \mathrm{~cm}$-width block to reduce the dose to the rectum and bladder until the total prescription dose for pelvic side wall of $50 \mathrm{~Gy}$ was reached. In cases in which tumor response was very poor, no CS was applied and whole pelvic EBRT was delivered up to $50 \mathrm{~Gy}$. For this purpose, tumor response was assessed every week by physical examination.

\section{Brachytherapy}

Brachytherapy was initiated during the second half of the EBRT course after application of CS with administration of 1-2 single-fraction sessions per week. For this purpose, MRI was performed before the first brachytherapy to confirm the indication for HBT and to aid for high-risk clinical target volume (HR-CTV) contouring $[6,15,16]$. Regarding the treatment devices itself, intracavitary applicators were either tandem/ovoid or tandem/cylinder. Additional interstitial catheters were inserted perineally or vaginally under TRUS guidance [15] with implantation being performed under saddle block anesthesia or local anesthesia and intravenous sedation.

Brachytherapy planning was CT- based (Fig. 1) with a slice thickness of $2 \mathrm{~mm}$ generated by a large bore CT simulator (Aquilion ${ }^{\mathrm{Tw}}$, Toshiba, Tokyo, Japan). Planning imaging was performed in lithotomy position with the applicators in situ and treatment planning was executed using the planning software Oncentra (Elekta, Veennendaal, The Netherlands). High-risk clinical target volume (HR-CTV) was not defined MRI-based [5, 6] because it was not possible to generate MRI for every single-fraction session but contoured based on CT imaging [12, 17, 18]. However, pre-interventional MRI was used as reference. All treatments were carried out by a ${ }^{192}$ Iridium remote 

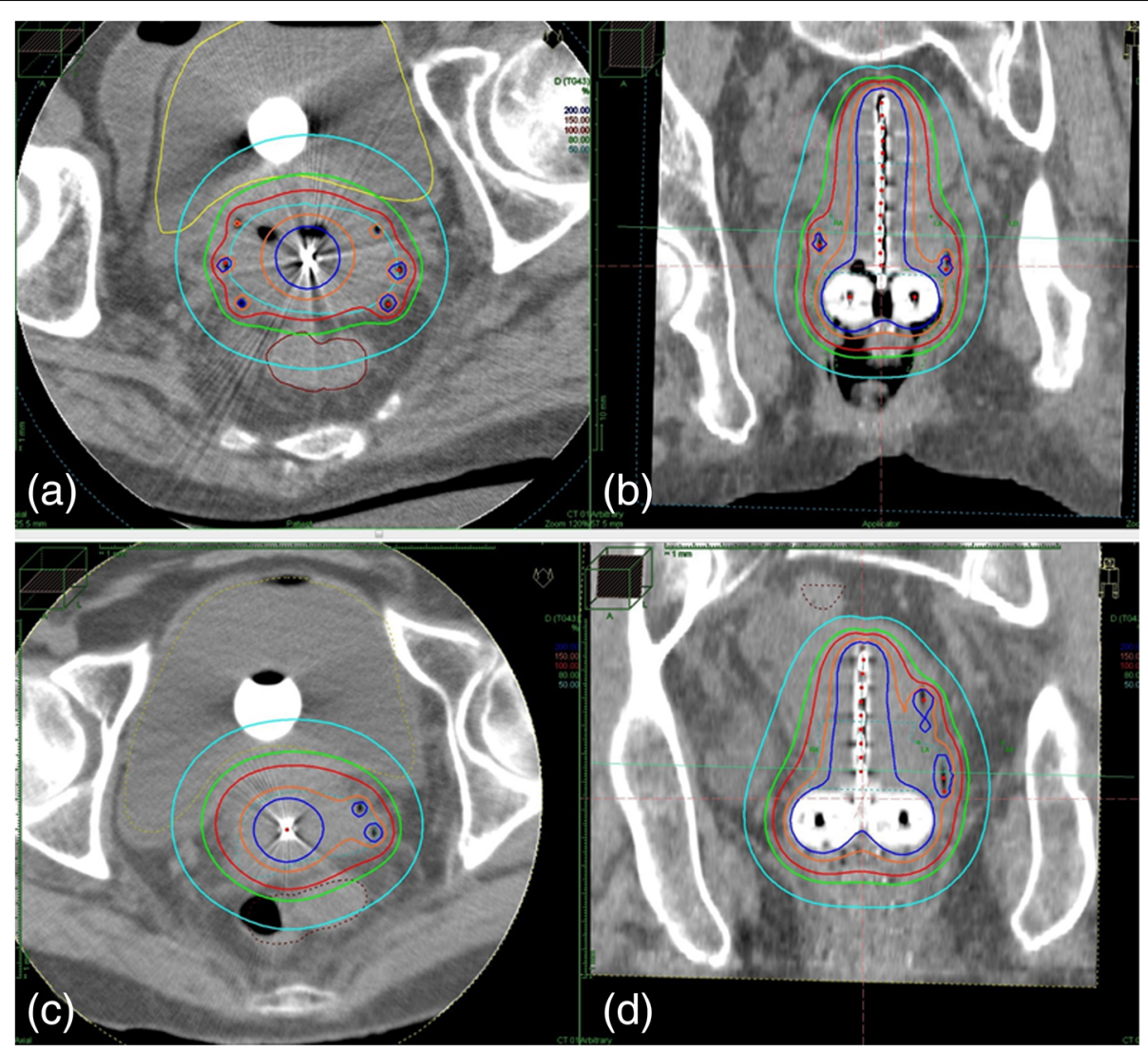

Fig. 1 Examples of dose distributions of computed tomography-based hybrid intracavitary and interstitial brachytherapy (HBT). a axial and (b) coronal images of HBT for a IIIB patient with bilateral parametrial invasion. In each side of the parametrium, three additional interstitial needles were inserted to cover lateral tumor extension. $\mathbf{c}$ axial and (d) coronal image of HBT for a IIIB patient with left parametrial invasion. Two interstitial needles were inserted in the left parametrium

after loading system (RALS, MicroSelectron HDR ${ }^{\mathrm{T}}$, Elekta, Veennendaal, The Netherlands).

The dosimetric goal was to deliver more than 6 Gy to the HR-CTV $D_{90}$ (dose covering at least $90 \%$ of the HR-CTV) while keeping doses to organs at risk (OARs) as low as possible. In some cases, if favorable tumor shrinkage was obtained after initial HBT, brachytherapy was completed with ICBT without additional interstitial catheter implantation.

\section{Dose calculation and Dosimetric indices}

In summing the dose of EBRT and HBT, the equivalent dose in 2 Gy fractions $\left(\mathrm{EQD}_{2}\right)$ [6] according to the LQ model $[19,20]$ was calculated according to the following formula:

$$
\mathrm{EQD} 2=\frac{\mathrm{Nd}\left(1+\frac{d}{\alpha / \beta}\right)}{1+\frac{2}{\alpha / \beta}}
$$

The parameter $N$ indicates the number of fractions and $d$ the dose per fraction. For calculating tumor and
OARs doses, $\alpha / \beta$ was assumed as $10 \mathrm{~Gy}$ and $3 \mathrm{~Gy}$, respectively. Dose contribution from CS was not taken into consideration [21].

The minimum dose covering $90 \%$ of the HR-CTV (HR-CTV $\mathrm{D}_{90}$ ) in $\mathrm{EQD}_{2}$ was used as the representative dose of HBT. In order to analyse further the relationship between dose distribution and local control (LC), an additional CTV-Corpus was defined as follows: HR-CTV was divided into two parts by the most cranial level of uterine cervix and the volume cranial to the level was defined as CTV-Corpus. Because no contrast enhancement agent was used in simulation CT imaging, the point at which the uterine volume expands was used as surrogate structure of the upper limit of uterine cervix. CTV-Corpus $\mathrm{V}_{100}$ (percentage of CTV-Corpus covered by $100 \%$ of the prescription dose) at the first brachytherapy was measured and its relation to LC, PSF, and OS was analysed.

\section{Follow-up}

All patients were evaluated weekly for acute adverse events during RT by physical examination and blood 
tests. Computed tomography and/or MRI and cytology were performed 3 months after completion of RT to evaluate initial tumor response and imaging was repeated every 3-6 months for the first 5 years and annually thereafter.

\section{Statistical analysis}

Overall survival (OS) was estimated from the start of RT to the date of death from any cause or censored at the last follow-up visit. Progression-free survival (PFS) was estimated from the start of RT to the date of any disease relapse or censored at the last follow-up visit. For LC calculation, central and parametrial relapse was considered as an event. Local control was estimated from the start of RT to the date of local relapse or censored at the last follow-up. Survival curves were estimated by using the Kaplan-Meier method and the differences were assessed by the log-rank test. A $p$ value $\leq 0.05$ was considered statistically significant. Factors with $p$ value $\leq 0.05$ were further analysed in the multivariate analysis by the Cox regression method. Cox proportional-hazards models were used to estimate hazard ratios. All statistical analyses were performed using IBM SPSS Statistics (version 18.0; SPSS, Inc., Chicago, IL).

This retrospective study was also approved by the Institutional Review Board of our hospital, the Ethics Committee of National Cancer Center Hospital, (approval number is 2015-359) according to the ethical standards laid down in the Declaration of Helsinki. Written informed consent was taken from all the participants included in this study before treatment.

\section{Results}

From January 2012 to November 2015, 42 consecutive uterine cervical cancer patients with histologically proven squamous cell carcinoma or adenocarcinoma were treated with definitive RT including HBT. Median follow-up for patients who were still alive at last follow-up visit was 23.2 months (range 13.2-71.4).

Treatment details are summarized in Table 2. Median volume of HR-CTV at initial HBT measured by CT was $37.1 \mathrm{ml}$ (range 12.1-89.2 ml). The median number of brachytherapy fractions was 4 (range 2-5). Median dose of HR-CTV $\mathrm{D}_{90}$ in $\mathrm{EQD}_{2}$ was $70.3 \mathrm{~Gy}$ (range 56.2-97.3 Gy).

The 2-year OS, PFS, and LC were 81.6, 54.4, and $80.2 \%$, respectively (Fig. 2). Nineteen patients experienced disease relapse with eleven patients having loco-regional failure and 15 patients distant metastasis. Of the seven patients with local recurrence (16.6\%), in five the failure site was the uterus and in two the parametria.

Factors potentially correlating with LC, PFS, or OS were analysed and summarised in Table 3. Factors showing statistical significance regarding LC were initial tumor size, radiologic feature of both ulceration and corpus invasion, HR-CTV volume at first brachytherapy, and mean HR-CTV $\mathrm{V}_{200}$ (percentage of the HR-CTV receiving at least $200 \%$ of the prescription dose). Tumors whose HR-CTV volume at first brachytherapy was $<40 \mathrm{ml}$ had better LC than HR-CTV volume $>40 \mathrm{ml}(2-\mathrm{y} \mathrm{LC}$ $95.5 \%$ vs $71.2 \%, p=0.032$ ). Tumors with mean HR-CTV $V_{200}>34 \%$ had better LC than mean HR-CTV $\mathrm{V}_{200}<34 \%$ (2-y LC $100 \%$ vs $76.4 \%, p=$ 0.042). A trend for improved LC was seen in patients with CTV-Corpus $\mathrm{V}_{100}>99 \%$ vs. CTV-Corpus $\mathrm{V}_{100}<$ $99 \%(2-y$ LC $100 \%$ vs $73.4 \%, p=0.062)$. Similarly, in sub-group analysis of patients with corpus invasion $(n$ $=26$ ) a trend for improved LC was seen in cases with CTV-Corpus $\mathrm{V}_{100}>99 \%$ vs. CTV-Corpus $\mathrm{V}_{100}<99 \%$ (2-y LC $100 \%$ vs $60.8 \%, p=0.098$, Fig. 3). In multi-variate analysis, patients showing radiologic features of both ulceration and corpus invasion had worse LC, PFS, and OS (Table 3). In addition, initial tumor size $>6 \mathrm{~cm}$ was also found out to be an adverse factor for PFS in multi-variate analysis.

Table 2 Treatment details, $n=42$

\begin{tabular}{|c|c|c|}
\hline & & $N=42$ \\
\hline Median dose prescribed to the whole pelvis (Gy) & & 30.6 (range, 26-50.4) \\
\hline Median brachytherapy fractions (n) & & 4 (range, 2-5) \\
\hline Median volume of HR-CTV at initial HBT (ml) & & 37.1 (range, 12.1-89.2) \\
\hline Median HR-CTV D90 in EQD $(G y)$ & & 70.3 (range, 56.2-97.3) \\
\hline Median HR-CTV V $100(\%)$ & & 95.9 (range, $79.3-100$ ) \\
\hline Median HR-CTV V $150(\%)$ & & 57.7 (range, 39.1-89.4) \\
\hline Median HR-CTV V $200(\%)$ & & 29.9 (range, 19.6-58.5) \\
\hline Median dose of bladder $\mathrm{D}_{2 \mathrm{cc}}$ in $\mathrm{EQD}_{2}(\mathrm{~Gy})$ & & 72.4 (range, 60.7-87.2) \\
\hline Median dose of rectum $\mathrm{D}_{2 c c}$ in $\mathrm{EQD}_{2}(\mathrm{~Gy})$ & & 64.5 (range, 47.6-75.2) \\
\hline \multirow[t]{2}{*}{ Concurrent chemotherapy } & Yes & 28 \\
\hline & No & 14 \\
\hline
\end{tabular}




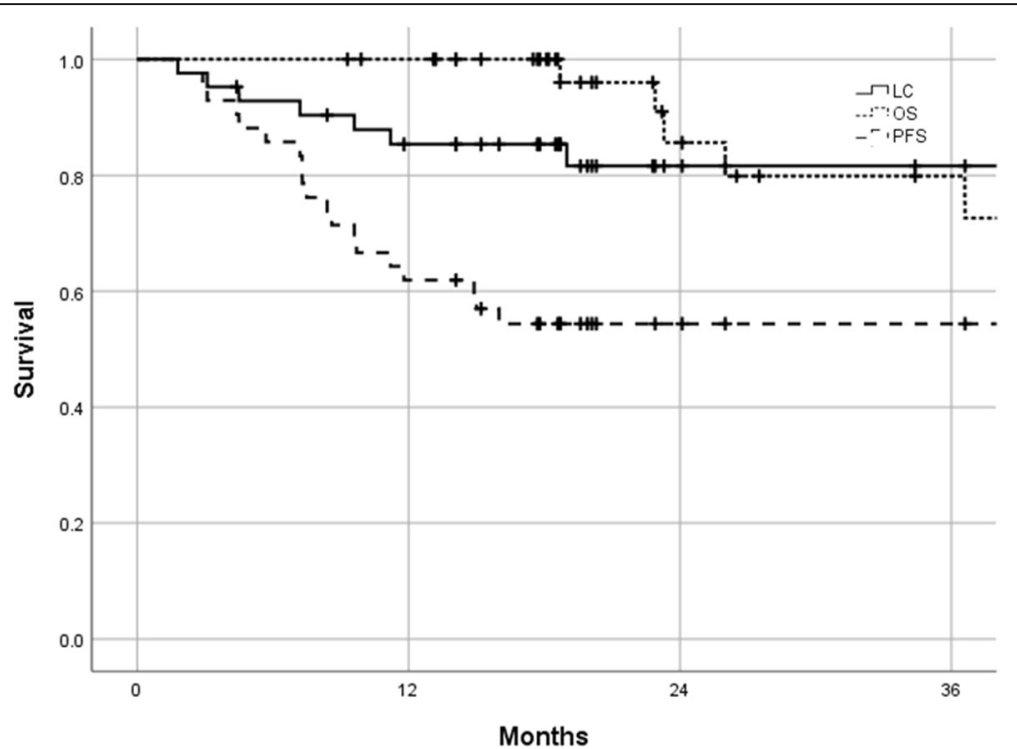

Fig. 2 Kaplan-Meier survival curves for local control (LC), progression-free survival (PFS), and overall survival (OS) of LAUCC patients treated by computed tomography-based hybrid intracavitary and interstitial brachytherapy

Table 3 Potential predictors influencing local control (LC), progression-free survival (PFS), and overall survival (OS)

\begin{tabular}{|c|c|c|c|c|c|c|c|c|c|c|c|c|}
\hline & \multicolumn{2}{|c|}{ 2-y LC (\%) } & \multicolumn{2}{|l|}{ LC } & \multicolumn{2}{|c|}{ 2-y PFS (\%) } & \multicolumn{2}{|l|}{ PFS } & \multicolumn{2}{|c|}{ 2-y OS (\%) } & \multicolumn{2}{|l|}{ OS } \\
\hline & $\begin{array}{l}\text { yes } \\
\text { (n) }\end{array}$ & $\begin{array}{l}\text { no } \\
(\mathrm{n})\end{array}$ & $\begin{array}{l}p \text { value } \\
\text { in uni. }\end{array}$ & $p$ value in multi. & yes & no & $p$ value in uni. & $p$ value in multi. & yes & no & $\begin{array}{l}p \text { value } \\
\text { in uni. }\end{array}$ & $\begin{array}{l}p \text { value in } \\
\text { multi. }\end{array}$ \\
\hline Scc vs Non-Scc & $\begin{array}{l}86.0 \\
(40)\end{array}$ & $\begin{array}{l}50 \\
(2)\end{array}$ & 0.101 & & $\begin{array}{l}54.6 \\
(40)\end{array}$ & $\begin{array}{l}50 \\
(2)\end{array}$ & 0.967 & & $\begin{array}{l}79.9 \\
(40)\end{array}$ & $\begin{array}{l}100 \\
(2)\end{array}$ & 0.669 & \\
\hline LN+ & $\begin{array}{l}89.5 \\
(20)\end{array}$ & $\begin{array}{l}78.8 \\
(22)\end{array}$ & 0.878 & & $\begin{array}{l}40.0 \\
(20)\end{array}$ & $\begin{array}{l}67.5 \\
(22)\end{array}$ & 0.052 & & $\begin{array}{l}73.5 \\
(20)\end{array}$ & $\begin{array}{l}84.5 \\
(22)\end{array}$ & 0.448 & \\
\hline $\begin{array}{l}\text { Initial tumor } \\
\text { size }>6 \mathrm{~cm}\end{array}$ & $\begin{array}{l}73.2 \\
(21)\end{array}$ & $\begin{array}{l}95.2 \\
(21)\end{array}$ & $0.042^{*}$ & & $\begin{array}{l}33.3 \\
(21)\end{array}$ & $75.9(21)$ & $0.005^{*}$ & $\begin{array}{l}p=0.043, \text { HR } 0.333 \\
95 \% \mathrm{Cl} 0.115-0.965\end{array}$ & $\begin{array}{l}75.3 \\
(21)\end{array}$ & $\begin{array}{l}85.0 \\
(21)\end{array}$ & $0.037^{*}$ & \\
\hline $\begin{array}{l}\text { Ulceration plus } \\
\text { corpus invasion }\end{array}$ & $\begin{array}{l}56.4 \\
(15)\end{array}$ & $\begin{array}{l}96.3 \\
(27)\end{array}$ & $0.006^{*}$ & $\begin{array}{l}p=0.017, \text { HR } 0.123 \\
95 \% \mathrm{Cl} 0.22-0.689\end{array}$ & $\begin{array}{l}26.7 \\
(15)\end{array}$ & $\begin{array}{l}70.0 \\
(27)\end{array}$ & $0.002^{*}$ & $\begin{array}{l}p=0.027, \text { HR } 0.340 \\
95 \% \mathrm{Cl} 0.131-0.882\end{array}$ & $\begin{array}{l}46.7 \\
(15)\end{array}$ & $\begin{array}{l}96.2 \\
(27)\end{array}$ & $0.001^{*}$ & $\begin{array}{l}p=0.003, \text { HR } 0.118, \\
95 \% \mathrm{Cl} 0.029-0.482\end{array}$ \\
\hline Hydronephrosis & $\begin{array}{l}77.1 \\
(10)\end{array}$ & $\begin{array}{l}87.1 \\
(32)\end{array}$ & 0.960 & & $\begin{array}{l}50.0 \\
(10)\end{array}$ & $\begin{array}{l}56.1 \\
(32)\end{array}$ & 0.981 & & $\begin{array}{l}88.9 \\
(10)\end{array}$ & $\begin{array}{l}76.9 \\
(32)\end{array}$ & 0.316 & \\
\hline Pyometra & $\begin{array}{l}91.7 \\
(12)\end{array}$ & $\begin{array}{l}81.4 \\
(30)\end{array}$ & 0.433 & & $\begin{array}{l}50.0 \\
(12)\end{array}$ & $\begin{array}{l}56.3 \\
(30)\end{array}$ & 0.554 & & $\begin{array}{l}68.8 \\
(12)\end{array}$ & $\begin{array}{l}84.1 \\
(30)\end{array}$ & 0.972 & \\
\hline $\begin{array}{l}\text { Combination } \\
\text { of weekly CDDP }\end{array}$ & $\begin{array}{l}80.3 \\
(28)\end{array}$ & $\begin{array}{l}92.3 \\
(14)\end{array}$ & 0.706 & & $\begin{array}{l}56.9 \\
(28)\end{array}$ & $\begin{array}{l}49.0 \\
(14)\end{array}$ & 0.917 & & $\begin{array}{l}81.8 \\
(28)\end{array}$ & $\begin{array}{l}76.6 \\
(14)\end{array}$ & 0.968 & \\
\hline $\begin{array}{l}\text { HR-CTV at initial } \\
\text { BT > } 40 \mathrm{ml}\end{array}$ & $\begin{array}{l}71.2 \\
(19)\end{array}$ & $\begin{array}{l}95.5 \\
(23)\end{array}$ & $0.032^{*}$ & & $\begin{array}{l}36.8 \\
(19)\end{array}$ & $\begin{array}{l}69.1 \\
(23)\end{array}$ & $0.026^{*}$ & & $\begin{array}{l}74.2 \\
(19)\end{array}$ & $\begin{array}{l}86.7 \\
(23)\end{array}$ & 0.297 & \\
\hline $\begin{array}{l}\text { HR-CTV } \\
D_{90}>70 \text { Gy }\end{array}$ & $\begin{array}{l}85.2 \\
(24)\end{array}$ & $\begin{array}{l}83.0 \\
(18)\end{array}$ & 0.888 & & $\begin{array}{l}45.5 \\
(24)\end{array}$ & $\begin{array}{l}66.7 \\
(18)\end{array}$ & 0.156 & & $\begin{array}{l}83.5 \\
(24)\end{array}$ & $\begin{array}{l}76.2 \\
(18)\end{array}$ & 0.820 & \\
\hline $\begin{array}{l}\text { CTV-Corpus } \\
V_{100}>99 \%\end{array}$ & $\begin{array}{l}100 \\
(13)\end{array}$ & $\begin{array}{l}73.4 \\
(29)\end{array}$ & 0.062 & & $\begin{array}{l}59.8 \\
(13)\end{array}$ & $51.7(29)$ & 0.457 & & $\begin{array}{l}83.9 \\
(13)\end{array}$ & $\begin{array}{l}76.8 \\
(29)\end{array}$ & 0.412 & \\
\hline $\begin{array}{l}\text { Mean HR-CTV } \\
V_{200}>34 \%\end{array}$ & $\begin{array}{l}100 \\
(14)\end{array}$ & $\begin{array}{l}76.4 \\
(28)\end{array}$ & $0.042^{*}$ & & $\begin{array}{l}55.6 \\
(14)\end{array}$ & $\begin{array}{l}53.6 \\
(28)\end{array}$ & 0.699 & & $\begin{array}{l}85.1 \\
(14)\end{array}$ & $\begin{array}{l}77.2 \\
(28)\end{array}$ & 0.396 & \\
\hline
\end{tabular}

PFS progression-free survival, $O S$ overall survival, uni.: univariate analysis, multi.: multivariate analysis, $L N+$ regional lymph node positive, $H R$ - $C T V$ high risk clinical target volume, $B T$ brachytherapy, $H R-C T V D_{90}$ minimum dose covering $90 \%$ of the HR-CTV, HR-CTV $V_{200}$ the percentage of the HR-CTV receiving higher than $200 \%$ of the prescribed dose 


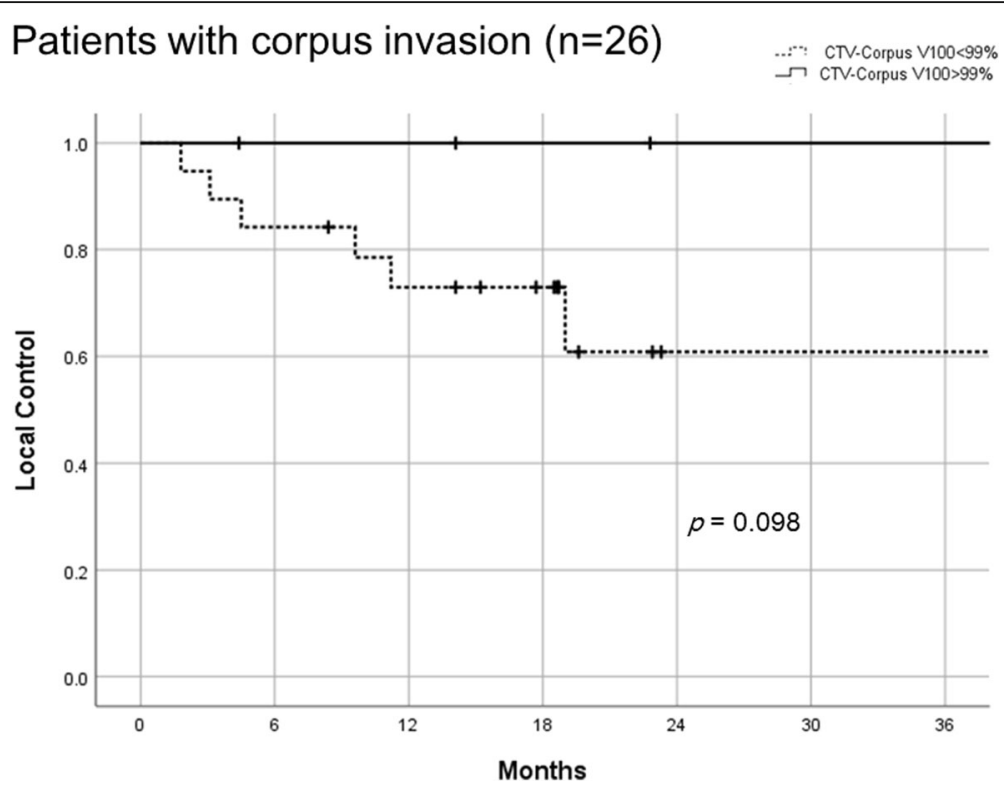

Fig. 3 Kaplan-Meier survival curves for local control (LC) for patients with corpus invasion $(n=26)$ stratified by CTV-Corpus $V_{100}$

Late adverse events $\geq$ grade 3 were seen in 3 patients; one patient suffered from grade 3 rectal bleeding and ileus requiring hyperbolic oxygen therapy $(\mathrm{HBO})$ and ileostomy, one experienced grade 3 rectal bleeding and vaginal ulcer requiring $\mathrm{HBO}$, and one developed rectovaginal fistula. Rectum $\mathrm{D}_{2 \mathrm{cc}}$ for those three patients were $66.7 \mathrm{~Gy}, 68.1 \mathrm{~Gy}$, and $67.5 \mathrm{~Gy}$, respectively. Patient with vaginal ulcer had extensive vaginal invasion, therefore, she was treated with tandem, cylinder, and additional interstitial needles in the brachytherapy. The vaginal ulcer was developed circumferentially in her upper third of vagina. Vaginal $D_{2 c c}$ for this patient was 157.3Gy which was higher than 145 Gy which was found to be a threshold for developing vaginal ulcer in our previous study [22].

\section{Discussion}

In this study the initial oncological results of LAUCC patients receiving primary RT including HBT were promising and consistent with other published experiences. Even though pretreatment median tumor diameter was $6 \mathrm{~cm}$, a 2 -y LC of $80.2 \%$ could be achieved despite the fact that tumor size represents a known adverse prognostic factor for primary RT in cervical cancer. At this, Toita et al. reported on a phase II multi-institutional prospective clinical trial using ICBT as mode of brachytherapy in patients with LAUCC generating a 2-year pelvic disease progression-free rate (PDPF) of $72 \%$ for tumors of $5-7 \mathrm{~cm}$ and of $54 \%$ for tumors larger than $7 \mathrm{~cm}$ [4]. Likewise, Pötter et al. reported a 2-y PDPF rate of $64 \%$ for patients treated by EBRT plus ICBT and whose initial tumor size was larger than $5 \mathrm{~cm}$ [3]. Therefore it may be concluded that the $2-y$ LC of $80 \%$ in our study was better than clinical outcomes associated with conventional ICBT for LAUCC. However, our yielded LC was not satisfactory compared to the other published HBT series reporting LC in the range of $90-95 \%[11,23]$. On the other hand, the 3-y LC for LAUCC patients who were treated in our institution with multi-catheter HDR interstitial brachytherapy (ISBT) was $87.8 \%$ in spite of having larger tumor than in the present study [24]. In this sense, it is conceivable that multi-catheter ISBT allows for more conformal tumor coverage than with $\mathrm{HBT}$, thereby improving target volume dose escalation and subsequently LC. The drawback of multicatheter ISBT, however, is that within a multi-fraction scheme it is logistically demanding and arduous for the patient requiring confinement to bed during multi-day treatments [25].

The actual indication of ICBT, HBT, and multi-catheter ISBT is a challenging topic which needs clinical experience in order to select the most appropriate brachytherapy modality depending on tumor size and shape [26]. Whatsoever, in our study lateral tumor extent was well controlled with HBT. On the other hand, uterine corpus recurrence was frequently observed in patients with local disease relapse. Although it did not reach statistical significance because of the small patient number analysed, CTV-Corpus $\mathrm{V}_{100}>99 \%$ was associated with a trend towards better LC (Table 3). In that regard, corpus invasion results in an irregular shape of the uterine corpus potentially prohibiting the adequate position of the tandem. Therefore, extra intra-corpus interstitial catheters may be necessary to adequately cover extensive tumor extent. 
In the current study, the median HR-CTV $\mathrm{D}_{90}$ was 70.3 Gy $\mathrm{EQD}_{2}$ which is lower than the 87 Gy recommended by Dimopoulos et al. [23] and the American Brachytherapy Society (ABS) guidelines $[27,28]$. However, HR-CTV $\mathrm{D}_{90}$ calculated in this study was derived from the simple addition of the whole pelvis RT dose and HBT while dose contribution from CS was completely ignored according to the Japan Society of Gynecologic Oncology guidelines [21]. At this, Tamaki et al. recently demonstrated that the HR-CTV $D_{90}$ generated by the combination of EBRT and ICBT in consideration of the dose contribution from CS is much higher than without counting for CS [29, 30]. Accordingly, the "corrected" median HR-CTV $\mathrm{D}_{90}$ in our series must be estimated greater than $70.3 \mathrm{~Gy}$ when ignoring respective national practice guidelines [21].

Concerning the impact of potential prognostic factors, parameters related to LC were initial tumor size $>6 \mathrm{~cm}$, HR-CTV volume $>40 \mathrm{ml}$ and mean HR-CTV $\mathrm{V}_{200}>34 \%$. In addition, multivariate analysis showed that having a morphological feature of both ulceration and corpus invasion had also a significant adverse impact (Table 3). A resembling result was depicted in the EMBRACE study indicating that infiltrative tumor growth responded unfavorably to CCRT when compared to expansive tumors [31]. Furthermore, we could show that tumors receiving mean HR-CTV $V_{200}>34 \%$ had improved LC. So far, no special attention has been paid in IGABT to the topic of high dose volumes receiving more than $100 \%$ of the prescribed reference dose with regard to outcomes correlation. Hereunto, the inherently non-homogeneous dose distribution in brachytherapy performs simultaneous intratumoral dose-boosting with no upper dose limits and a very sharp dose fall-off gradient outside the target volume [32]. The latter is of particular importance as it facilitates the application of very high doses to central tumor areas which might experience increased radioresistance due to hypoxic tumor microenvironment. This dose escalation might be an effective approach to counteract the negative impact of tumor hypoxia as prognostic factor for survival in patients with uterine cervical cancer [33].

One patient experienced development of vaginal ulcer which is relatively rare late radiation-related adverse effect. This patient had extensive vaginal invasion which required tandem and cylinder to cover the target volume in the brachytherapy. When patients have their disease in the vaginal wall, it is difficult to distinguish between pure vaginal ulcer or ulcer-like necrotic tumor shrinkage. On the other hand, vaginal wall $D_{2 c c}$ of this patient was $157.3 \mathrm{~Gy}$ which was higher than a previously reported threshold of $145 \mathrm{~Gy}$ for late vaginal ulcer [22].

There are several limitations in this study. Firstly, HR-CTV was contoured based on CT imaging and might therefore be larger than when defined by MRI [17]. As a result, the comparison with data generated by
MRI-based treatment planning must be done cautiously. In addition, our dose schedule was different from the standard dose schedule of the GEC-ESTRO [6] or ABS guidelines [27, 28] not allowing an unconditional extrapolation of the clinical outcome data when using different dose schedules. Finally, this is a retrospective study from a single institution with a limited number of patients. Further investigations are warranted to verify the findings demonstrated in this analysis.

\section{Conclusion}

For locally advanced uterine cervical cancer patients, HBT can provide favorable LC associated with an acceptable late toxicity profile.

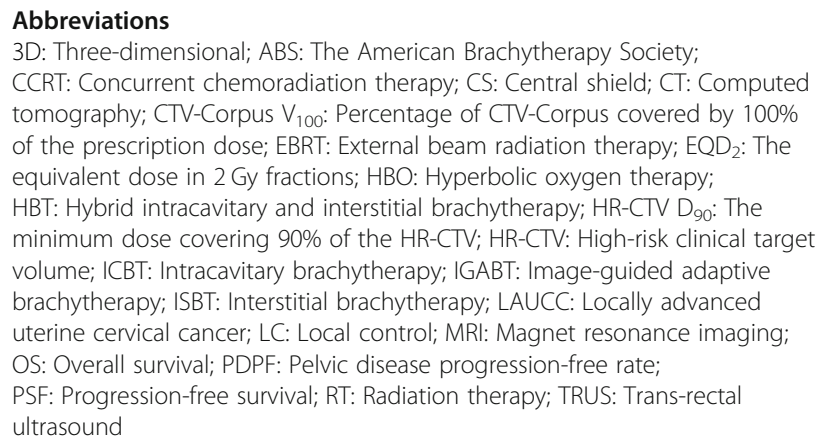

\section{Acknowledgements}

Not applicable.

\section{Funding}

This study was partially supported by the Japan Agency for Medical Research and Development, AMED, the National Cancer Center Research and Development Fund (26-A-18 and 26-A-28), and JSPS KAKENHI Grant Number $15 \mathrm{~K} 19836$. The role of the funding bodies include data analysis and supporting publication fee of this manuscript.

\section{Availability of data and materials}

The datasets generated and analyzed during the current study are not publicly available because it was not a big project to have such a public datasets, but are available from the corresponding author on reasonable request.

\section{Authors' contributions}

NM gathered clinical data and analyzed it. KK, SS, KT, TK, RU, KT, and KI performed HBT for cervical cancer patients. NT made a great contribution in terms of article editing and data analysis. The other authors, $\mathrm{Yl}, \mathrm{HI}, \mathrm{YN}, \mathrm{KM}$, $\mathrm{KY}, \mathrm{TK}$, and $\mathrm{Jl}$ participated in acquisition and interpretation of data. All authors read and approved the final manuscript.

\section{Ethical approval and consent to participate}

This retrospective study was also approved by the Institutional Review Board of our hospital, the Ethics Committee of National Cancer Center Hospital, (approval number is 2015-359) according to the ethical standards laid down in the Declaration of Helsinki. Written informed consent was taken from all the participants included in this study before treatment.

Consent for publication

Not applicable.

Competing interests

The authors declare that they have no competing interests. 


\section{Publisher's Note}

Springer Nature remains neutral with regard to jurisdictional claims in published maps and institutional affiliations.

\begin{abstract}
Author details
'Department of Radiation Oncology, National Cancer Center Hospital, 5-1-1 Tsukiji, Chuo-ku, Tokyo 104-0045, Japan. ${ }^{2}$ Department of Gynecologic Oncology, National Cancer Center Hospital, 5-1-1 Tsukiji, Chuo-ku, Tokyo 104-0045, Japan. ${ }^{3}$ Department of Radiology, Kyoto Prefectural University of Medicine, Kyoto, Japan. ${ }^{4}$ Department of Radiology, Osaka Medical College, Takatsuki, Osaka, Japan. ${ }^{5}$ Department of Radiotherapy and Oncology, Goethe-University Frankfurt, Frankfurt am Main, Germany.
\end{abstract}

Received: 30 October 2017 Accepted: 1 March 2019

Published online: 12 March 2019

\section{References}

1. Han K, Milosevic M, Fyles A, Pintilie M, Viswanathan AN. Trends in the utilization of brachytherapy in cervical cancer in the United States. Int J Radiat Oncol Biol Phys. 2013;87:111-9.

2. Tod M, Meredith WJ. Treatment of cancer of the cervix uteri, a revised Manchester method. Br J Radiol. 1953;26:252-7.

3. Pötter R, Dimopoulos J, Georg P, Lang S, Waldhäusl C, Wachter-Gerstner N, et al. Clinical impact of MRI assisted dose volume adaptation and dose escalation in brachytherapy of locally advanced cervical cancer. Radiother Oncol. 2007:83:148-55.

4. Toita T, Kitagawa R, Hamano T, Umayahara K, Hirashima Y, Aoki Y, et al. Phase II study of concurrent chemoradiotherapy with high-dose-rate intracavitary brachytherapy in patients with locally advanced uterine cervica cancer: efficacy and toxicity of a low cumulative radiation dose schedule. Gynecol Oncol. 2012;126:211-6.

5. Haie-Meder C, Pötter R, Van Limbergen E, Briot E, De Brabandere M, Dimopoulos J, et al. Recommendations from Gyneacological (GYN) GECESTRO working group (I): concepts and terms in 3D image based 3D treatment planning in cervix cancer brachytherapy with emphasis on MRI assessment of GTV and CTV. Radiother Oncol. 2005;74:235-45.

6. Pötter R, Haie-Meder C, Van Limbergen E, Barillot I, De Brabandere M, Dimopoulos J, et al. Recommendations from Gyneacological (GYN) GECESTRO working group (II): concepts and terms in 3D image-based treatment planning in cervix cancer brachytherapy-3D dose volume parameters and aspects of 3D image-based anatomy, radiation physics, radiobiology. Radiother Oncol. 2006;78:67-77.

7. Dimopoulos JC, Kirisits C, Petric P, Georg P, Lang S, Berger D, et al. The Vienna applicator for combined intracavitary and interstitial brachytherapy of cervical cancer: clinical feasibility and preliminary results. Int J Radiat Oncol Biol Phys. 2006:66:83-90.

8. Nomden CN, de Leeuw AA, Moerland MA, Roesink JM, Tersteeg RJ, Jürgenliemk-Schulz IM. Clinical use of the Utrecht applicator for combined intracavitary/interstitial brachytherapy treatment in locally advanced cervical cancer. Int J Radiat Oncol Biol Phys. 2012;82:1424-30.

9. Wakatsuki M, Ohno T, Yoshida D, Noda SE, Saitoh J, Shibuya K. Intracavitary combined with CT-guided interstitial brachytherapy for locally advanced uterine cervical cancer: introduction of the technique and a case presentation. J Radiat Res. 2011:52:54-8.

10. Fokdal L, Tanderup K, Hokland SB, Røhl L, Pedersen EM, Nielsen SK, et al Clinical feasibility of combined intracavitary/interstitial brachytherapy in locally advanced cervical cancer employing MRI with a tandem/ring applicator in situ and virtual preplanning of the interstitial component. Radiother Oncol. 2013;107:63-38.

11. Fokdal L, Sturdza A, Mazeron R, Haie-Meder C, Tan LT, Gillham C, et al. Image guided adaptive brachytherapy with combined intracavitary and interstitial technique improves the therapeutic ratio in locally advanced cervical cancer: analysis from the retroEMBRACE study. Radiother Oncol. 2016;120:434-40.

12. Murakami N, Kato S, Nakano T, Uno T, Yamanaka T, Sakurai H, et al. A phase I/II clinical trial for the hybrid of intracavitary and interstitial brachytherapy for locally advanced cervical cancer. BMC Cancer. 2016:16:640-7.

13. Kuroda Y, Murakami N, Morota M, Sekii S, Takahashi K, Inaba K, et al. Impact of concurrent chemotherapy on definitive radiotherapy for women with FIGO IIIB cervical cancer. J Radiat Oncol. 2012;53:588-93.
14. Murakami N, Kasamatsu T, Wakita A, Nakamura S, Okamoto H, Inaba K, et al. $\mathrm{CT}$ based three dimensional dose-volume evaluations for high-dose rate intracavitary brachytherapy for cervical cancer. BMC Cancer. 2014;14:447-53.

15. Schmid MP, Pötter R, Brader P, Kratochwil A, Goldner G, Kirchheiner K, et al. Feasibility of transrectal ultrasonography for assessment of cervical cancer. Strahlenther Onkol. 2013;189:123-8.

16. Johannes CA, Dimopoulos JC, Gertrude S, et al. MRI assessment of cervical cancer for adaptive radiotherapy. Strahlenther Onkol. 2009;185:282-7.

17. Viswanathan AN, Dimopoulos J, Kirisits C, Berger D, Pötter R. Computed tomography versus magnetic resonance image-based contouring in cervical cancer brachytherapy: results of a prospective trial and preliminary guidelines for standardized contours. Int J Radiat Oncol Biol Phys. 2007;68:491-8.

18. Ohno T, Wakatsuki M, Toita T, Kaneyasu Y, Yoshida K, Kato S, et al. Recommendations for high-risk clinical target volume definition with computed tomography for three-dimensional image-guided brachytherapy in cervical cancer patients. J Radiat Res. 2017:58:341-50.

19. Dale RG. The application of the linear-quadratic dose-effect equation to fractionated and protracted radiotherapy. Br J Radiol. 1985;58:515-28.

20. Bentzen SM, Dörr W, Gahbauer R, Howell RW, Joiner MC, Jones B, et al. Bioeffect modeling and equieffective dose concepts in radiation oncology terminology, quantities and units. Radiother Oncol. 2012;105:266-8.

21. Ebina $Y$, Yaegashi N, Katabuchi H, Nagase S, Udagawa Y, Hachisuga T, et al. Japan Society of Gynecologic Oncology guidelines 2011 for the treatment of uterine cervical cancer. Int J Clin Oncol. 2015;20:240-8.

22. Murakami N, Kasamatsu T, Sumi M, Yoshimura R, Harada K, Kitaguchi M, et al. Vaginal tolerance of $\mathrm{CT}$ based image-guided high-dose rate interstitial brachytherapy for gynecological malignancies. Radiat Oncol. 2014;9:31-9.

23. Dimopoulos JC, Lang S, Kirisits C, Fidarova EF, Berger D, Georg P, et al. Dose-volume histogram parameters and local tumor control in magnetic resonance image-guided cervical cancer brachytherapy. Int J Radiat Oncol Biol Phys. 2009;75:56-63.

24. Murakami N, Kobayashi K, Kato T, Nakamura S, Wakita A, Okamoto H, et al. The role of interstitial brachytherapy in the management of primary radiation therapy for uterine cervical cancer. J Contemp Brachytherapy. 2016:8:391-8.

25. Itami J, Hara R, Kozuka T, Yamashita H, Nakajima K, Shibata K, et al. Transperineal high-dose-rate interstitial radiation therapy in the management of gynecologic malignancies. Strahlenther Onkol. 2003;179:737-41.

26. Yoshida K, Yamazaki H, Kotsuma T, Takenaka T, Ueda MM, Miyake S, et al. Simulation analysis of optimized brachytherapy for uterine cervical cancer: can we select the best brachytherapy modality depending on tumor size? Brachytherapy. 2016;15:57-64.

27. Viswanathan AN, Thomadsen B. American brachytherapy society cervical Cancer recommendations committee; American brachytherapy society. American Brachytherapy Society consensus guidelines for locally advanced carcinoma of the cervix. Part I: general principles Brachytherapy. 2012;11:33-46.

28. Viswanathan AN, Beriwal S, De Los Santos JF, Demanes DJ, Gaffney D, Hansen J, et al. American brachytherapy society consensus guidelines for locally advanced carcinoma of the cervix. Part II: high-dose-rate brachytherapy. Brachytherapy. 2012;11:47-52.

29. Tamaki T, Ohno T, Noda S, Kato S, Nakano T. Filling the gap in central shielding: three-dimensional analysis of the EQD2 dose in radiotherapy for cervical cance with the central shielding technique. J Radiat Res. 2015:56:804-10.

30. Tamaki T, Noda S, Ohno T, Kumazaki Y, Kato S, Nakano T. Dose-volume histogram analysis of composite EQD2 dose distributions using the central shielding technique in cervical cancer radiotherapy. Brachytherapy. 2016:15:598-606.

31. Yoshida K, Jastaniyah N, Sturdza A, Lindegaard J, SegedinB MU, et al. Assessment of parametrial response by growth pattern in patients with International Federation of Gynecology and Obstetrics stage IIB and IIIB cervical cancer: analysis of patients from a prospective, multicenter trial (EMBRACE). Int J Radiat Oncol Biol Phys. 2015;93:788-96.

32. Milickovic N, Tselis N, Karagiannis E, Ferentinos K, Zamboglou N. Iridium-Knife: Another knife in radiation oncology. Brachytherapy. 2017; Epub ahead of print.

33. Fyles AW, Milosevic $M$, Wong $R$, Kavanagh MC, Pintilie $M$, Sun $A$, et al. Oxygenation predicts radiation response and survival in patients with cervix cancer. Radiother Oncol. 1998:48:149-56. 